\title{
A new genus of fossil frogs (Amphibia: Anura: Hylidae) from the Miocene of the northern Great Plains (USA), with a commentary on vertebrate diversity ${ }^{1}$
}

\author{
Lauren E. Brown²and Evan S. Brown ${ }^{3}$
}

\begin{abstract}
We describe a new genus of fossil frog from the Miocene, Valentine Formation, Barstovian (13 - 14.5 million years ago) of northern Nebraska in the northern Great Plains USA. This frog was originally described as Pseudacris nordensis in 1964. The large, diverse genus Pseudacris is composed of 18 other species, all of which are extant. A total of 164 specimens (7 fossils, 114 dry skeletons, 43 cleared and stained specimens) from 17 museums and collections was examined for the new genus and the 18 extant species of Pseudacris. Diagnostic characteristics of the ilia differentiate the distinct new fossil genus from all extant species of Pseudacris. The new genus is known from three locations in the basin of the Niobrara River. Two extant species $(P$. clarkii and $P$. crucifer) are also known from several fossils of the same stratigraphic horizon as the new genus. Co-occurrence of the new genus with P. clarkii and P. crucifer in the same horizon clearly indicates that they were markedly distinct 13-14.5 million years ago. We propose that the northern Great Plains may have been a center of diversity for terrestrial vertebrates during the Miocene, and discuss models for speciation, the first step in the evolution of a new genus.
\end{abstract}

Key Words: New genus, fossil frog, Hylidae, ilium, Miocene, Valentine Formation, Barstovian, Niobrara River, Nebraska, northern Great Plains, diversity, speciation.

The frog family Hylidae is the largest amphibian family in the world with 945 species presently recognized by Frost (2014). The family is known as far back as the Paleocene (Estes and Reig, 1973) and is distributed throughout much of the New World, Europe, southern Asia, and Australia, but is absent from most of Africa, India, and northern Asia (Duellman and Trueb, 1986). Most species are moderate to relatively small, although there are some large species. Hylids are primarily an arboreal group and they are thus known as "treefrogs." The most obvious adaptation for this habitat is the presence of adhesive toe pads. However, some species are terrestrial and a few are fossorial or aquatic.

Frog fossils are usually incomplete in North America (Holman, 2003) and quite rare. Unfortunately, paleontological research does not have the luxury of large sample sizes (e.g. even the diagnosis [genus and species combined] of the famed Tyrannosaurus rex Osborn, 1905 was based only on a single incomplete fossilized skeleton). Often, only the distinctive elongate ilium of the pelvic girdle is available for North American fossil frogs (Lynch, 1963; Holman,

\footnotetext{
${ }^{1}$ Submitted on August 5, 2014. Accepted on August 30, 2014. Last revisions received on October 1, 2014.

${ }^{2}$ School of Biological Sciences, Campus Box 4120, Illinois State University, Normal, Illinois 61790-4120 USA

${ }^{3}$ School of Liberal Arts, Ivy Tech Community College, 1440 E. $35^{\text {th }}$ Avenue, Gary, Indiana, 46409

USA. E-mail: ebrown56@ivytech.edu
}

DOI: 10.9784/LEB2(3)Brown.01

Electronically available on October 17, 2014. Mailed on October 17, 2014. 
2003), but sometimes other skeletal elements are found. Studies by a number of researchers [e.g. Auffenberg (1956), Chantell (1964), Holman (2003), Lynch (1963), and others] have shown the usefulness and reliability of the ilium in fossil taxonomic research in the Hylidae. The small ilia are often found in loosely consolidated or unconsolidated sediments of old stream beds and quarry dumps (Hibbard, 1949). To isolate fossils, several careful, laborious screenings and washings of large quantities of sediments are necessary followed by final removal of the specimens with a small moist brush or forceps. Some of the ilia may be incomplete (e.g., lacking a shaft) or worn in various areas.

The hylid genus Pseudacris Fitzinger, 1843 (chorus frogs) is composed of 18 extant and one fossil species. Fifteen of the extant species are primarily terrestrial, with a few species that occasionally climb. The three remaining extant species do not climb and are highly fossorial, having an unusual method of burrowing involving exclusive use of their enlarged muscular forelimbs (Brown et al., 1972; Brown, 1978; Brown and Means, 1984).

In contrast to the extant Pseudacris (which is one of the most researched groups of frogs in North America), the fossil P. nordensis has almost been ignored. Chantell (1964) originally described the species from a distinct posterior portion of a left ilium discovered at the Norden Bridge Quarry (Miocene, Valentine Formation, Barstovian) of the northern Great Plains in Brown County, north-central Nebraska, USA. Holman (1987) reported a second, nearly complete right ilium from the Egelhoff Local Fauna (Miocene, Valentine Formation, Barstovian) from adjacent Keya Paha County, Nebraska not far from the type locality. Holman (1995) reported a third ilium (lacking part of the shaft and parts of the dorsal and ventral acetabular expansions) from the Miocene, Valentine Formation, Barstovian, Annie's Geese Cross Local Fauna in Knox County, northeastern Nebraska. Another posterior portion of a left ilium of a fourth specimen (Miocene, Valentine Formation, Barstovian, Norden Bridge Quarry) was deposited in the University of Nebraska State Museum (UNSM 54027). Voorhies (1990) indicated this fossil is quite similar to the holotype and designated it as $P$. nordensis.

Chantell (1964) emphasized that "Pseudacris nordensis is an extinct and unique form and not simply a large Mio-Pliocene representative of an extant Pseudacris." Subsequently, Holman (2003) suggested that P. nordensis probably represents a new genus, and Parmley et al. (2010) indicated the dorsal ilial crest of the species is "distinctly characteristic." J. Alan Holman died eight years ago (2006) and there have been no changes of the systematic status of $P$. nordensis since the original description was published a half century ago. Consequently, because of the marked distinctiveness of the ilia, we describe a new genus for $P$. nordensis. This is part of a continuing research program on the systematics and evolution of chorus frogs (e.g. Brown et al., 1972; Brown 1978; Brown and Means, 1984; Paukstis and Brown 1987, 1991). 


\section{Methods}

Most museums have relatively few or no dry skeletons or cleared and stained specimens of extant species because of the extensive work and expense necessary for their preparation. Hence it was necessary to contact 17 museums and collections to obtain loans or to examine specimens at the home museum. Their acronyms are: California Academy of Sciences (CAS); Museum of Vertebrate Zoology, University of California, Berkeley (MVZ); Carnegie Museum of Natural History (CM); Cornell University Museum of Vertebrates (CUMV); Field Museum of Natural History (FMNH); Florida Museum of Natural History, University of Florida (UF); Museum of Comparative Zoology, Harvard University (MCZ); Natural History Museum, University of Illinois, administered by the Illinois Natural History Survey (UIMNH); Natural History Museum of Los Angeles County (LACM); Museum of Zoology, University of Michigan (UMMZ); Michigan State University Museum (MSUM for extant species, MSU VP. for fossils); University of Nebraska State Museum (UNSM); National Museum of Natural History, Smithsonian Institution (USNM); Museum of Geology, South Dakota School of Mines and Technology (SDSM); Texas Cooperative Wildlife Collection, Texas A\&M University (TCWC); Peabody Museum of Natural History, Yale University (YPM); Lauren E. Brown Collection (LEB).

The ilia of a total of 164 museum specimens were examined: 7 fossils; 114 dry skeletons of extant species; and 43 cleared and stained specimens of extant species (see Appendix). Total numbers for each species examined were: Pseudacris brachyphona (7); P. brimleyi (5); P. cadaverina (7); P. clarkii (15); P. crucifer (9); P. feriarum (4); P. fouquettei (1); P. illinoensis (16); P. kalmi (3); P. maculata (7); P. nigrita (6); P. nordensis (4); P. ocularis (8); P. ornata (17); P. regilla complex (13); $P$. streckeri (30); and P. triseriata (12). Only mature specimens were examined. They were from a diversity of locations in 21 states of the USA, plus Canada and Mexico (USA-California, Florida, Georgia, Illinois, Kansas, Kentucky, Maryland, Michigan, Nebraska, North Carolina, New Jersey, New York, Ohio, Pennsylvania, South Carolina, South Dakota, Texas, Utah, Virginia, West Virginia, and Wyoming; Canada-Alberta; MexicoBaja California Norte). None of the skeletons of the $P$. regilla complex were identified by species other than " $P$. regilla" when prepared. Thus, the ilia of the three forms in the complex (i.e., $P$. hypochondriaca, $P$. regilla, $P$. sierra) could not be individually characterized.

The ilia of all specimens were examined several times in detail under a Bausch and Lomb (zoom lens) dissecting microscope. Cleared and stained preparations were examined in glycerin in a finger bowl to prevent glistening and facilitate handling. Lengths of fossil ilia were measured with a dial vernier caliper under the dissecting scope.

We follow Mayr and Ashlock (1991) who emphasized that a diagnosis should be a brief listing of only the most important characters. No synonyms of 
P. nordensis exist; hence, a synonymy was not constructed. In the past, there has been some variation in anatomical terminology applied to the ilium. We follow the nomenclature in Chantell (1964).

\section{Systematics \\ Family Hylidae Rafinesque, 1815}

\section{Geophryne Brown and Brown, New Genus (Figures 1-2)}

Type Species. Pseudacris nordensis Chantell, 1964:217. Holotype: UNSM 61007 (examined by authors), posterior $6.0 \mathrm{~mm}$ of left ilium, collected July 1962 by a field team of the University of Notre Dame.

Type Locality. Norden Bridge Quarry, SE 1/4 SW 1/4 Sec. 33 T33N R23W, Brown County, in the northern Great Plains of north-central Nebraska, USA (Chantell, 1964).

Horizon. Lower Miocene, basal deposits of the Valentine Formation, elevation $2171 \mathrm{ft}$ (661.7 m), Medial Barstovian North American Land Mammal Age (Voorhies, 1990).

Referred Species. Geophryne nordensis (Chantell, 1964). New combination from Pseudacris nordensis Chantell (1964).

Referred Specimens. UNSM 54027 left ilium, posterior $3.8 \mathrm{~mm}$; UNSM 61007 (holotype of species), left ilium, posterior $6.0 \mathrm{~mm}$; MSU VP. 1105, right ilium, nearly complete, length $=13.2 \mathrm{~mm}$ (Figures 1-2); MSU VP. 1374, left ilium, incomplete, length $=10.6 \mathrm{~mm}$. All four fossils were examined by the authors.

Diagnosis. The new genus Geophryne is distinguished from Pseudacris by the combination of the following diagnostic characters of the ilia: ilium exceptionally robust; ilial shaft with prominent dorsal crest; three separate dorsal protuberances (on single dorsal prominence), one much larger, more posterior, and more lateral than the two smaller ones; dorsal prominence elevated dorsally as a longitudinal, sharply defined ridge, wider posteriorly, oblique to midline of ilium, slightly higher than and medial to dorsal protuberances; acetabular fossa far from elevated summit of dorsal prominence; posterior slope of dorsal prominence extended as a ridge posteriorly onto lateral surface of dorsal acetabular expansion; large dorsal protuberance attached to vertical stalk-like ridge laterally.

Comparison with Pseudacris. The diagnostic characters for Geophryne are contrasted (sequentially) in the remaining species of Pseudacris as follows: ilium not robust, often gracile; no elevated dorsal crest on ilial shaft; one or no dorsal protuberance on dorsal prominence; no elevated ridge on dorsal prominence; upper limit of dorsal prominence much closer to acetabular fossa; posterior slope of dorsal prominence terminated anterior to dorsal acetabular expansion or fused with an often deep saddle-shaped ridge continuous with the 
dorsal rim of the dorsal acetabular expansion; dorsal protuberance without vertical stalk-like ridge.
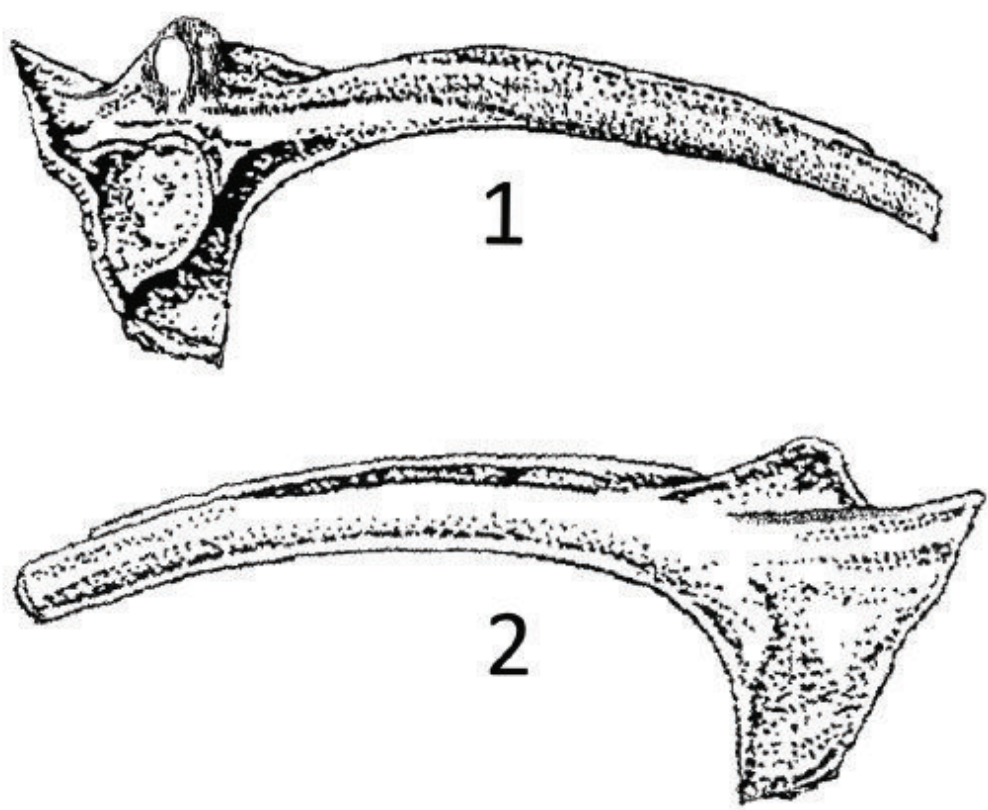

Figures 1-2. Geophryne nordensis MSU VP. 1105, nearly complete right ilium (length = $13.2 \mathrm{~mm}$ ) from the Egelhoff Local Fauna, Keya Paha County in the northern Great Plains of north-central Nebraska, USA. Horizon: Miocene, Valentine Formation, Barstovian. The enlarged portion of the ilium is posterior. 1. lateral view, 2. medial view. Originally published in the Journal of Vertebrate Paleontology 7:112 fig. 2 (C) 1987. Reprinted and distributed with permission of the Society of Vertebrate Paleontology. Figures 1 and 2 were modified extensively to improve precision by Alex M. Zarek.

Description. Ilium large; in lateral view, acetabular fossa a large, deeply conical depression, strawberry-like in lateral profile, peripheral rim thick and protrudent particularly anteriorly and anteroventrally, rim extending anteriorly nearly as far as anterior edge of most anterior dorsal protuberance; ventral acetabular expansion somewhat small, slightly concave laterally, thick along posterior edge tapering to a thin anterior edge which extends well beyond the rim of the acetabular fossa; dorsal acetabular expansion small, thick, obliquely pointed posterodorsally, posterior and anterior edges straight, posterior surface with slightly elongated shallow vertical concavity; ilial shaft thick, oval in crosssection (higher than wide); wide, elongate, lateral groove extending from middle of ilial shaft to above acetabular fossa, bordered dorsally by a prominent, thick ridge extending from middle of shaft to anterodorsal edge of rim of acetabular fossa; dorsal ilial crest clearly distinguishable throughout its length in medial view and in lateral view except that greater thickness of crest posteriorly somewhat obscures its distinction from shaft, posteriorly crest rounded dorsally, but anteriorly the dorsal edge thinner and sharp, crest somewhat oblique, 
directed medially particularly in central region; dorsal prominence exceptionally well developed, its anterior slope gradual terminating medial to dorsal crest of shaft, posterior slope becoming narrower as it extends onto lateral surface of dorsal acetabular expansion, ridge at summit of dorsal prominence curved and directed posteriorly toward midline of ilium; groove between this ridge and dorsal protuberances; posterior dorsal protuberance oval (higher than wide), elevated, on lateral surface of dorsal prominence (not at summit); vertical stalklike ridge of posterior dorsal protuberance wide, fused laterally with dorsal prominence, and extended ventrally terminating on body of ilium; narrower, vertical stalk-like ridge of most anterior dorsal protuberance shorter terminating on dorsal prominence; on medial side of ilium the anterior rim of dorsal acetabular expansion extends anterolaterally as a ridge toward the end of anterior slope of dorsal prominence; ventral to this rim extension and posterior to the shaft, ilium relatively flat.

Etymology. The prefix Geo is an English transcription that refers to the Greek term meaning "earth." The suffix phryne is an English transcription that refers to the Greek term which means "toad" (Chisholm, 1911). Hence, Geophryne means "earth toad" or "toad of the earth."4

Species descriptions. Chantell (1964) and Holman (1987, 1995, 2003) provided descriptions for the species nordensis.

Distribution of Geophryne (Figure 3). The new genus is known from three localities in the basin of the Niobrara River in the northern Great Plains of northcentral and northeastern Nebraska, USA (Figure 3). Chantell (1964) first reported the new genus from the Norden Bridge Quarry, SE 1/4 SW 1/4 Sec. 33, T33N, R23W, Brown County, in north-central Nebraska, and NUSM 54027 was collected at the same locality. Holman (1987) reported a second locality also in north-central Nebraska at $1.6 \mathrm{~km} \mathrm{~N}$ of the Niobrara River, Franklin H. Egelhoff property, SE corner of NE 1/4 SW 1/4 Sec. 29 T33N R23W, Keya Paha County.

${ }^{4}$ In the past, phryne has been used as the suffix for some other frog generic names (e.g. Rhinophrynus, Gastrophryne, Pseudophryne, Heleophryne, Arenophryne, Melanophryne, Paedophryne). Thus, many herpetologists are familiar with the term. However, most may be unaware that phryne was also commonly used as a derogatory name for prostitutes in ancient Greece. This is most notable for the famous Greek courtesan Mnesarete of the 4th century B.C. who was called "Phryne" (Chisholm, 1911). She was born in Thespiae but lived most of her life in Athens. Phryne was known for her great beauty as well as her extraordinary wealth. In 336 B.C. Alexander the Great destroyed the walls of Thebes. Subsequently, Phryne made an offer to rebuild the walls if the phrase "Destroyed by Alexander, restored by Phryne the courtesan" was engraved thereon, but she was turned down by the authorities (Chisholm, 1911). She was the model for Apelles' famous picture of Aphrodite Anadyomene, and is also thought to have been the model for Praxiteles' statue of the Cnidian Aphrodite. During her trial for profaning the Eleusinian mysteries, when it seemed there would be an unfavorable verdict, her counselor tore down her robe exposing her shapely breasts. The judges were apparently so moved by her beauty that she was acquitted. However, it is thought that this story may be embellished. Statues of Phryne and Aphrodite, both by Praxiteles, were placed next to one another in a temple in Thespiae (Chisholm, 1911). 
The third locality in northeastern Nebraska is NW 1/4 Sec. 23, T33N, R3W, Knox County (Holman, 1995).

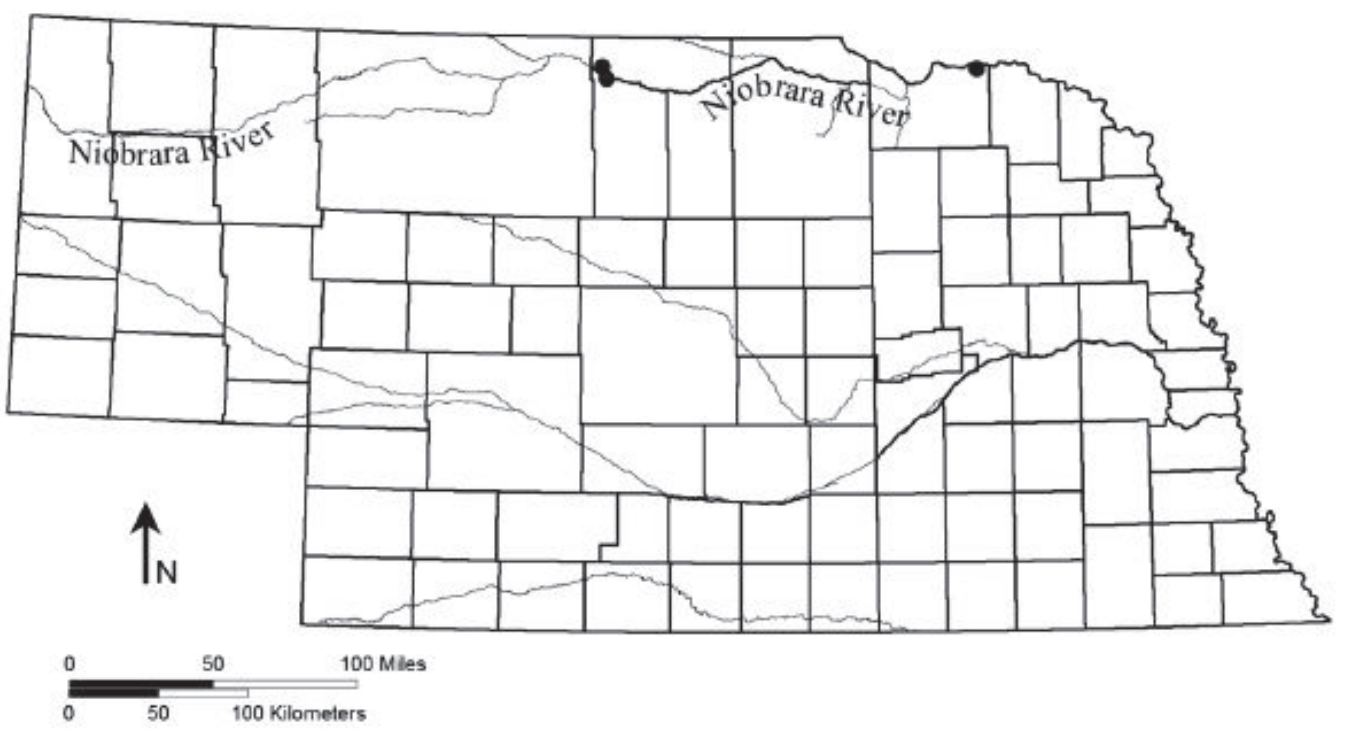

Figure 3. Distribution of known paleontological sites for ilia of four specimens of the new genus Geophryne Brown and Brown in three counties (Brown, Keya Paha, and Knox) in the northern Great Plains of Nebraska, USA. These localities are located in the basin of the Niobrara River (illustrated) in deposits of the Miocene, Valentine Formation, Barstovian. Cartography by C. K. Williams.

\section{Discussion}

Chantell (1964) presented his diagnosis as a "Definition" for the then new species $P$. nordensis, and Holman (2003) subsequently provided an "Emended Diagnosis." Our diagnosis and description for the new genus Geophryne drew from some characters of their diagnoses and descriptions. However, we modified those characters (sometimes considerably) to improve clarity and precision, and included characteristics uncovered through our own observations.

Chantell (1964) reported a left ilium of $P$. clarkii (UNSM 61008) from the Barstovian of the Norden Bridge Quarry. Two more ilia (left and right) of $P$. clarkii were identified by Chantell (1971) from the Egelhoff Local Fauna. (Geophryne is from the same horizon.) Holman (1978) also identified two left ilia (different sizes) of $P$. clarkii (SDSM 8716) from the Miocene, Valentine Formation, Barstovian of south-central South Dakota (just north of the Missouri River and not far from the localities for Geophryne in northern Nebraska). Furthermore, Chantell (1971) and Holman (1976) reported three fossils of Hyla crucifer ( $=P$. crucifer which is also extant) from the Egelhoff Local Fauna where Geophryne was found. The co-occurrence of G. nordensis with $P$. clarkii and P. crucifer in the same horizon in the Miocene clearly indicates that they were markedly distinct 13-14.5 million years ago, the age of the Medial Barstovian indicated by Voorhies (1990). 
As of 1990 a total of 36 paleontological sites were found in the Barstovian of Nebraska containing a diverse vertebrate fauna, e.g., sturgeon, alligator gar, huge catfish, alligators, giant tortoises, boas, a wolverine-like mustelid, horses, tapirs, camels, rhinoceroses, mastodons, etc. (Voorhies, 1990). Among the amphibians of the area, 21 species have been reported as fossils, eight of which are in the family Hylidae (Chantell, 1964, 1971; Holman, 1976, 1987; Voorhies, 1990; Voorhies et al., 1987). In contrast, only nine species of amphibians are presently extant in the area (Conant and Collins, 1998; Stebbins, 2003.) Thus, the Barstovian of Nebraska is one of the richest vertebrate paleontological areas in North America. At least 34 of the fossil species have been designated as the type species of new genera (Voorhies, 1990). Thus, our description of the new genus Geophryne further enriches the taxonomic paleontological diversity of this important formation.

Perhaps the great diversity may in part reflect the warm climate of the Valentine Formation Barstovian proposed by Holman and Sullivan (1981) and Voorhies (1990) based on the presence of a number of species of reptiles with extant closest relatives that are adapted to warm climates with mild winters. The best indicators of this are the giant land tortoises (Geochelone) common in the Barstovian (Holman and Sullivan, 1981). Hibbard (1960) pointed out that extant giant Geochelone cannot survive freezing weather. Thus, he was convinced that the presence of these cold-blooded tortoises is an important indicator of mild winters.

Voorhies (1990) indicated that these vertebrate fossils have "exceptional importance in understanding the history of the North American Fauna especially in the Great Plains." The exceptional diversity thus also suggests the northern Great Plains may have been a center for speciation in the Lower Miocene. Blair (1954) suggested an "isolation by abandonment" model for speciation of mammals in the central grasslands of the USA during the Pleistocene that involved climatic fluctuations resulting in northward and southward distributional range shifts in the grasslands. During range retraction due to adverse climatic changes, some smaller populations were left behind in more favorable isolated environmental pockets. Continued isolation and differentiation of such populations could result in speciation. Later, Blair (1965) pointed out the isolation of northern and southern relicts from more widely distributed ranges of species of amphibians in various regions of North America. These relicts were thought to be the results of post-Wisconsin climatic fluctuations. In some cases, the disjuncts were considered to have undergone speciation. It would seem appropriate to extend the "isolation by abandonment" model to terrestrial vertebrates (except for highly vagile species) during the Miocene in the northern Great Plains.

We suggest another model for speciation in the northern Great Plains during the Miocene. Aquatic species and riverine-adapted terrestrial species of vertebrates could have moved a considerable distance along rivers (e.g. 
precursor to the Niobrara) and their tributaries over time. Subsequent flooding and/or droughts could have eliminated most populations but left isolated relicts in certain areas not subjected to such environmental extremes. Continued isolation and differentiation of these relicts could have resulted in speciation, the first step in what could be the evolution of a new genus.

\section{Acknowledgments}

We thank: the following curators and collection managers for providing loans of specimens Jens Vindum (CAS), Carol Spencer (MVZ), Stephen Rogers (CM), Chuck Dardia (CUMV), Alan Resetar (FMNH), Max Nickerson and Ken Krysko (UF), Jonathan Losos (MCZ), Chris Phillips (UIMNH), Nefty Camacho (LACM), Ron Nussbaum and Greg Schneider (UMMZ), Laura Abraczinskas (MSUM and MSU VP), Kevin de Queroz and Robert Wilson (USNM), Darrin Pagnac (SDSM), Toby Hibbitts (TCWC), Gregory Watkins-Colwell (YPM); Jason Head, Curator of Vertebrate Paleontology, UNSM for permission to visit the museum to examine the holotype of Pseudacris nordensis and other fossils; George Corner, Collection Manager, UNSM for assistance with fossils at the Museum; Herpnet for providing a database for searching for dry bones and cleared and stained specimens catalogued in museums; Ed Mockford for systematic advice; Robert Nelson for geological advice; Alex Zarek for extensively modifying the artwork in Figures 1 and 2; Crystal $\mathrm{K}$. Williams for cartography (Figure 3) and electronically preparing the figures; Jill Brown, Angelo Capparella, Ed Mockford, Anne (Brown) Nash, Robert Nelson, Dennis Parmley, and Don Shepard for critically reading the manuscript; and Craig Gatto, Director, School of Biological Sciences, Illinois State University for providing funds for publication costs and student help.

\section{Literature Cited}

Auffenberg, W. 1956. Remarks on some Miocene anurans from Florida, with a description of a new species of Hyla. Breviora No. $52.11 \mathrm{pp}$.

Blair, W. F. 1954. Mammals of the Mesquite Plains Biotic District in Texas and Oklahoma, and speciation in the central grasslands. The Texas Journal of Science 6:235-264.

Blair, W. F. 1965. Amphibian speciation. pp. 543-556. In, H. E. Wright, Jr. and D. G. Frey (Editors). The Quaternary of the United States, A Review Volume for the VII Congress of the International Association for Quaternary Research. Princeton University Press. Princeton, New Jersey, USA. $\mathrm{x}+922 \mathrm{pp}$.

Brown, L. E. 1978. Subterranean feeding by the chorus frog Pseudacris streckeri (Anura: Hylidae). Herpetologica 34:212-216.

Brown, L. E., H. O. Jackson, and J. R. Brown. 1972. Burrowing behavior of the chorus frog, Pseudacris streckeri. Herpetologica 28:325-328.

Brown, L. E. and D. B. Means. 1984. Fossorial behavior and ecology of the chorus frog Pseudacris ornata. Amphibia-Reptilia 5:261-273.

Chantell, C. J. 1964. Some Mio-Pliocene hylids from the Valentine Formation of Nebraska. The American Midland Naturalist 72:211-225. http://dx.doi.org/10.2307/2423224

Chantell, C. J. 1971. Fossil amphibians from the Egelhoff Local Fauna in north-central Nebraska. Contributions from the Museum of Paleontology, The University of Michigan 23:239-246. http://dx.doi.org/10.2307/2423224

Chisholm, H. (Editor). 1911. The encyclopaedia Britannica. A dictionary of arts, sciences, literature and general information. 11th Edition, 21:545, University Press. Cambridge, England, UK and New York, New York, USA. XIV + 984 pp. (Scholars’ Edition).

Conant, R. and J. T. Collins. 1998. A field guide to reptiles \& amphibians, eastern and central North America. 3rd Edition. Houghton Mifflin Company. Boston, Massachusetts and New York, New York, USA. XVIII + 616 pp.

Duellman, W. E. and L. Trueb. 1986. Biology of Amphibians. McGraw-Hill Book Company. New York, NY, USA, etc. XVII + 670 pp. 
Estes, R. and O. A. Reig. 1973. The early fossil record of frogs, a review of the evidence. pp. 1163. In, J. L. Vial (Editor). Evolutionary Biology of the Anurans, Contemporary Research on Major Problems. University of Missouri Press. Columbia, Missouri, USA. XII + 470 pp.

Fitzinger, L. 1843. Systema Reptilium, Amblyglossae. Braumüller et Seidel Bibliopolas, Vindobonae, Austria (1973 reprint, Society for the Study of Amphibians and Reptiles). vi + $106+$ VI pp.

Frost, D. R. 2014. Amphibian species of the world: an online reference. Version 6.0 (22 July 2014), http://research.amnh.org/herpetology/amphibia/index.html. American Museum of Natural History. New York, New York, USA.

Hibbard, C. W. 1949. Techniques of collecting microvertebrate fossils. Contributions from the Museum of Paleontology, The University of Michigan 8:7-19.

Hibbard, C. W. 1960. An interpretation of Pliocene and Pleistocene climates in North America. Annual Report of the Michigan Academy of Sciences, Arts and Letters 62:5-30.

Holman, J. A. 1976. The herpetofauna of the Lower Valentine Formation, north-central Nebraska. Herpetologica 32:262-268.

Holman, J. A. 1978. Herpetofauna of the Bijou Hills Local Fauna (Late Miocene: Barstovian) of South Dakota. Herpetologica 34:253-257.

Holman, J. A. 1987. Herpetofauna of the Egelhoff site (Miocene: Barstovian) of north-central Nebraska. Journal of Vertebrate Paleontology 7:109-120. http://dx.doi.org/10.1080/02724634.1987.10011646

Holman, J. A. 1995. A Late Medial Miocene herpetofauna from northeastern Nebraska. Herpetological Natural History 3:143-150.

Holman, J. A. 2003. Fossil frogs and toads of North America. Indiana University Press. Bloomington and Indianapolis, Indiana, USA. XIII + $246 \mathrm{pp}$.

Holman, J.A. and R.M. Sullivan. 1981. A small herpetofauna from the type section of the Valentine Formation (Miocene: Barstovian), Cherry County, Nebraska. Journal of Paleontology 55:138144.

Lynch, J. D. 1963. Additional evidence for the recognition of Limnaoedus (Amphibia: Hylidae). Copeia 1963:566-568. http://dx.doi.org/10.2307/1441482

Mayr, E. and P. D. Ashlock. 1991. Principles of Systematic Zoology. Second Edition. McGrawHill, Inc. New York, NY, USA, etc. XX +475 pp.

Osborn, H. F. 1905. Tyrannosaurus (sic) and other Cretaceous carnivorous dinosaurs. Bulletin of the American Museum of Natural History 21:259-265.

Parmley, D., K. B. Hunter, and J. A. Holman. 2010. Fossil frogs from the Clarendonian (Late Miocene) of Oklahoma, U.S.A. Journal of Vertebrate Paleontology 30:1879-1883. http://dx.doi.org/10.1080/02724634.2010.521603

Paukstis, G. L. and L. E. Brown. 1987. Evolution of the intercalary cartilage in chorus frogs, genus Pseudacris (Salientia: Hylidae). Brimleyana 13:55-61.

Paukstis, G. L. and L. E. Brown. 1991. Evolutionary trends in the morphology of the intercalary phalanx of anuran amphibians. Canadian Journal of Zoology 69:1297-1301. http://dx.doi.org/10.1139/z91-182

Rafinesque, C. S. 1815. Analyse de la nature, ou, tableau de l'univers et des corps organisés. Jean Barravecchia. Palermo, Sicily. 224 pp.

Stebbins, R.C. 2003. A field guide to western reptiles and amphibians. Third Edition. Houghton Mifflin Company. Boston, Massachusetts and New York, NY, USA. XIII + 533 pp.

Voorhies, M. R. 1990. Vertebrate paleontology of the proposed Norden Reservoir area, Brown, Cherry, and Keya Paha counties, Nebraska. Technical Report 82-09, Division of Archaeological Research, University of Nebraska. Lincoln, Nebraska, USA. V + 138 + 593 pp.

Voorhies, M.R., J.A. Holman, and X. Xiang-Xu. 1987. The Hottell Ranch rhino quarries (basal Ogallala: medial Barstovian), Banner County, Nebraska. Part I: Geologic setting, faunal lists, lower vertebrates. Contributions to Geology, University of Wyoming 25:55-69. 


\section{Appendix}

List of specimens examined (fossils, dry skeletons, and cleared and stained specimens). Each number represents one specimen, except for "(2)" which indicates two specimens catalogued under a single museum number. Fossils are indicated by "(F)".

Geophryne nordensis - UNSM 54027 (F), 61007 (F, holotype for species), MSU VP. 1105 (F), 1374 (F).

Pseudacris brachyphona - UIMNH 12102, 95120-95122, UMMZ 132869, 132871, 153970; P. brimleyi - CM 18646, UMMZ 153972, 153973, USNM 547934, 547935; P. cadaverina - MVZ 4416, 78196, 79283, 79284, CM 63668, LACM 163353, UMMZ 180467; P. clarkii - FMNH 11927, 11931, 11945, 38141, 46885, 46892, 98254, UIMNH 32875, 32881, UMMZ 153974, 153975, UNSM 61008 (F), SDSM 8716 (2, F), TCWC 81982; P. crucifer - FMNH 98181, 207617, 275717, UF 686, 11864, 11876, 51809, 63883, 158872; $P$. feriarum - CM 33619, 92259, USNM 312777, 312778; P. fouquettei - CM 37697; P. illinoensis - FMNH 275729, 275730, 275736, MSUM HE.13168, HE.13175, HE.13177, HE.13179, HE.13181, HE.13183, HE.13187, HE.13189, HE.13190, HE.13193, SH.1924, LEB S1, S2; P. kalmi - CM 30877, 30879, USNM 292181; P. maculata - CAS 18400, 18401, MVZ 78875-78877, UMMZ 176705, MSUM SH. 1357; P. nigrita - UF 11852, 18886, 57954, 57956, 60672, 61034; P. ocularis - CM 126490, UIMNH 13169, UMMZ 153983, 153984, 153988, 153990, 153992, MSUM SH. 823; P. ornata - MVZ 232173-232175, UF 11878, 39059, 45367, 48472, 48473, 56323, MCZ 28784, UIMNH 13136, LACM 165171, UMMZ 132880, 132882, 132883, 181902, 181903; P. regilla complex - MVZ 4444, 58196, 69522, 79075-79077, 129922, 129923, UIMNH 5682, LACM 166633, 166634, UMMZ 128078, 153862; P. streckeri - CM 37693, CUMV 12981, 12992, 13009, MCZ 16142, 16144 (2), UIMNH 12913, UMMZ 154141-154145, TCWC 78208, 78210-78218, 81945, YPM 6213, 6214, 6216, 6217, 6841, 6879; P. triseriata - FMNH 22017, 98257-98260, MSUM HE.12832, HE.12953, SH.2853 UIMNH 32877-32879, UMMZ 170264. 